\title{
Dietary glycotoxins affect scavenger receptor expression and the hormonal profile of female rats
}

\author{
Antonios Chatzigeorgiou ${ }^{1,2}$, Eleni Kandaraki ${ }^{3,4}$, Christina Piperi ${ }^{3}$, Sarantis Livadas ${ }^{4}$, \\ Athanasios G Papavassiliou ${ }^{3}$, Michael Koutsilieris' ${ }^{1}$, Apostolos Papalois ${ }^{5}$ \\ and Evanthia Diamanti-Kandarakis ${ }^{4}$ \\ ${ }^{1}$ Department of Experimental Physiology, University of Athens Medical School, Athens, Greece \\ ${ }^{2}$ Department of Internal Medicine III and Institute of Physiology, Dresden University of Technology, Dresden, \\ Germany \\ ${ }^{3}$ Department of Biological Chemistry, University of Athens Medical School, Athens, Greece \\ ${ }^{4}$ Endocrine Unit, Third Department of Internal Medicine, Sotiria Hospital, University of Athens Medical School, \\ Athens, Greece \\ ${ }^{5}$ Experimental Research Centre, ELPEN Pharmaceuticals, Athens, Greece
}

Correspondence should be addressed to E Diamanti-Kandarakis Email

e.diamanti.kandarakis@ gmail.com

\begin{abstract}
The levels of advanced glycation end products (AGEs) are increased under conditions of impaired glucose metabolism and/or oxidative stress, promoting insulin resistance and other endocrine abnormalities. AGEs play a major role in the pathogenesis of several diseases such as diabetes, atherosclerosis, polycystic ovary syndrome and Alzheimer's disease, contributing to progressive ageing. Receptor-based clearance of AGEs by the receptor for AGE (RAGE) and/or the macrophage scavenger receptor A (SR-A) is considered as a main factor for the regulation of the concentration of AGEs under these conditions. This study aimed to investigate the expression of RAGE (AGER) and SR-A (MSR1) under high/low-dietary AGE conditions in vivo and their potential contribution to the metabolic and sex hormonal profile of female rats. Female Wistar rats were fed a low-AGE or high-AGE diet for 3 months. Serum samples were collected at baseline and at the completion of the 3-month period for the measurements of metabolic and hormonal parameters. Peripheral blood mononuclear cells (PBMCs) were isolated for the determination of the expression of RAGE and SR-A. The high-AGE diet-fed rats exhibited increased glucose, insulin and testosterone levels as well as decreased oestradiol and progesterone levels compared with the low-AGE diet-fed ones, thus indicating a metabolic and hormonal dysregulation attributed to high-AGE dietary exposure. The expression of RAGE was significantly down-regulated in the PBMCs of the high-AGE diet-fed rats $(P=0.041)$, and it was correlated negatively with insulin and testosterone levels and positively with progesterone levels. The expression of SR-A was also decreased in the high-AGE diet-fed rats to marginal significance. Decreased monocytic expression of scavenger receptors such as RAGE and SR-A may result in a higher deposition of AGEs in peripheral endocrine tissues, thus promoting endocrine-related abnormalities and diseases.
\end{abstract}

\author{
Key Words \\ - AGES \\ - RAGE \\ - SR-A \\ - PCOS \\ - insulin resistance \\ - endocrine dysregulation
}

Journal of Endocrinology (2013) 218, 331-337
(C) 2013 Society for Endocrinology Printed in Great Britain
Published by Bioscientifica Ltd 


\section{Introduction}

Advanced glycation end products (AGEs) are a heterogeneous group of cross-linking molecules, formed from a non-enzymatic reaction of reducing sugars with the amino groups of proteins and lipids via the Maillard reaction. AGEs are highly reactive molecules, which may induce many injuries in cells and tissue structures by the formation of insoluble cross-links, reduction of enzymatic activity, induction of oxidative stress, damage to nucleic acids and activation of cytotoxic pathways (Niwa 2006, Tan et al. 2011). AGEs are accumulated under conditions of impaired glucose metabolism or oxidative stress, and thus their levels are predominantly increased during ageing and diabetes mellitus (DM) and they seem to play a pivotal role in the pathogenesis of other diseases such as atherosclerosis, chronic renal failure, polycystic ovary syndrome (PCOS) and Alzheimer's disease (Mukhopadhyay \& Mukherjee 2005, Tan et al. 2011). Furthermore, data obtained from humans and experimental animals indicate that exogenous food-ingested AGEs, present in highly thermolyzed fat-containing Westernized diets, result in elevated serum levels and increased tissue deposition of AGEs that can provoke the initiation or progression of insulin resistance and other endocrine abnormalities (Diamanti-Kandarakis et al. 2007a, Cai et al. 2008, de Assis et al. 2009). Similarly, low-glycotoxin dietfed mice exhibit extended lifespan and reduced oxidative stress, while restriction of AGEs improves insulin resistance in T2DM patients (Cai et al. 2007, Uribarri et al. 2011).

The receptor for AGE (RAGE (AGER)), a member of the immunoglobulin superfamily, which interacts with numerous ligands including AGEs, is expressed on the surface of a variety of cell types, including endothelial cells, smooth muscle cells, lymphocytes, monocytes and neurons (Mukhopadhyay \& Mukherjee 2005), although it also exists in a soluble form, as the product of proteolytic cleavage of RAGE from the cell surface or alternative splicing (Sourris \& Forbes 2009). The interaction of RAGE with AGEs generates Reactive oxygen species (ROS) via the activation of NADPH oxidase and pro-inflammatory transcription factor $\mathrm{NF \kappa B}$, which, in turn, engages pro-inflammatory and pro-oxidative signalling events in cells. NFKB may contribute to the development of a pro-inflammatory and pro-oxidative state by stimulating the expression of numerous target genes, such as tissue factor, vascular cell adhesion molecule-1 (VCAM1), p21Ras, ERK1/2 (MAPK3/1) and RAGE itself (Tanaka et al. 2000, Mukhopadhyay \& Mukherjee 2005). Furthermore, AGE-RAGE signalling through the activation of $N F \kappa B$ has been reported to regulate the expression of inflammatory cytokines (such as tumour necrosis factor $\alpha$ (TNF $\alpha$ ) and interleukin 1), PAI-1 and endothelin-1, contributing to the development of several inflammationrelated conditions and diseases such as atherosclerosis, diabetic nephropathy and retinopathy (Murphy et al. 2005, Diamanti-Kandarakis et al. 2007b).

AGEs being generated through the long-term exposure of proteins to glucose also behave as active ligands for scavenger receptors, including class A scavenger receptor (SR-A) and class B scavenger receptors such as CD36 and SR-BI (Miyazaki et al. 2002). Macrophage SR-A, the product of the MSR1 gene, is a multifunctional, multiligand pattern recognition receptor with roles in innate immunity, apoptotic cell clearance and age-related degenerative pathologies, such as atherosclerosis and Alzheimer's disease. Endogenous SR-A ligands are commonly polyanionic and include modified lipoproteins, AGEs and extracellular matrix proteins (Neyen et al. 2009). Therefore, the potential role of SR-A as a defence mechanism of the regulation of AGEs during AGE-accumulating pathologies should be defined (Cai et al. 2012).

We have previously shown that high-AGE diets have an impact on the metabolic as well as hormonal profile of female rats, in addition to the deposition of AGEs in the ovarian tissue (Diamanti-Kandarakis et al. 2007a). The aim of the present study was to investigate the expression of the scavenger receptors RAGE and SR-A (MSR1) under a high-AGE environment and their potential involvement or contribution to the dysregulation of insulin and female hormone levels.

\section{Materials and methods}

\section{Animals and diets}

Female Wistar rats (ten per group, aged 21 days at the start of feeding) were fed a low-AGE- or high-AGE-containing diet as described previously (Kandaraki et al. 2012).

A single standard rat chow (AIN-93G, Bioserve, Frenchtown, NJ, USA), containing $18 \%$ protein, 58\% carbohydrate, $7.5 \%$ fat and $3.73 \mathrm{kcal} / \mathrm{g}$ and prepared normally at $190^{\circ} \mathrm{C}$ for $30 \mathrm{~min}$, was used for the preparation of the diets as described previously (DiamantiKandarakis et al. 2007a). The high-in-AGE (H-AGE) diet contained $76.0 \pm 15.3 \mathrm{mg}$ carboxymethyllysine $(\mathrm{CML}) / 100 \mathrm{~g}$ sample (or $436.9 \pm 88.1 \mathrm{mg} \mathrm{CML} / 100 \mathrm{~g}$ protein), $205.32 \pm 22.25 \mathrm{mg}$ fructoselysine/100 g sample (or $1179.98 \pm 127.90 \mathrm{mg}$ fructoselysine/100 g protein)

Published by Bioscientifica Ltd. 
and $52.68 \pm 5.71 \mathrm{mg}$ furosine $/ 100 \mathrm{~g}$ sample (or 302.78 $\pm 32.82 \mathrm{mg}$ furosine/ $100 \mathrm{~g}$ protein). The same diet mixture was also prepared without heating. This preparation, considered a low-in-AGE (L-AGE) diet, consisted equivalent macronutrient and micronutrient and energy contents, but it contained $1.3 \pm 0.4 \mathrm{mg} \mathrm{CML} / 100 \mathrm{~g}$ sample (or $7.7 \pm 2.2 \mathrm{mg} \mathrm{CML} / 100 \mathrm{~g}$ protein), $104.58 \pm 3.08 \mathrm{mg}$ fructoselysine/100 g sample (or $601.01 \pm 17.7 \mathrm{mg}$ fructoselysine/100 g protein) and $26.83 \pm 0.79 \mathrm{mg}$ furosine $/ 100 \mathrm{~g}$ sample (or $154.22 \pm 4.54 \mathrm{mg}$ furosine/100 $\mathrm{g}$ protein).

The rats were housed under controlled conditions $\left(21-22^{\circ} \mathrm{C}, 55-65 \%\right.$ humidity and $12 \mathrm{~h}$ light: $12 \mathrm{~h}$ darkness cycle) four to five per cage at the ELPEN S.A. Experimental Research Centre (Athens, Greece), and were given pelleted food and water ad libitum. Animal care and experimental procedures were approved by the Institutional Animal Care and Use Committee and conformed to the 'Guide for the Care and Use of Laboratory Animals' (Department of Health, Education and Welfare, Athens, Greece).

The study was completed by 3 months. The rats were killed by the administration of $20 \mathrm{mg} / \mathrm{ml}$ xylazine hydrochloride and $100 \mathrm{mg} / \mathrm{ml}$ ketamine hydrochloride, under anaesthesia with ether, followed by blood sample collection.

\section{Laboratory procedures and assays}

Blood samples were collected from the rats and immediately centrifuged at $4{ }^{\circ} \mathrm{C}$. Serum samples were used immediately or stored at $-80^{\circ} \mathrm{C}$ until analysis. The buffy coat of each sample was collected and diluted in a balanced salt solution, and platelet-free peripheral blood mononuclear cells (PBMCs) were isolated by using a Ficollplus gradient (STEMCELL Technologies, Grenoble, France) and stored at $-80^{\circ} \mathrm{C}$ for later use.

The concentrations of insulin and progesterone were measured using ELISAs (Biovendor Laboratory Medicine, Czech Republic and Neogen Corporation, Lexington, KY, USA respectively). The concentrations of rat oestradiol $\left(\mathrm{E}_{2}\right)$ and testosterone were quantified using commercially available ELISA kits (Calbiotech Inc., Spring Valley, CA, USA), while serum AGE levels $(\mathrm{U} / \mathrm{ml})$ were evaluated using competitive CML-specific ELISA as described previously (Diamanti-Kandarakis et al. 2005). The concentrations of serum glucose $(\mathrm{mg} / \mathrm{dl})$ were measured with the glucose oxidase technique (Linear Diagnostics, Montgat, Spain).

\section{Preparation of cell lysates}

PBMCs were lysed according to the method of Chatzigeorgiou et al. (2010) in 1\% Triton $(50 \mathrm{mmol} / \mathrm{l}$
Tris, $\mathrm{pH} 7.4,150 \mathrm{mmol} / \mathrm{l} \mathrm{NaCl}, 0.02 \%$ sodium azide and $1 \%$ Triton X-100) supplemented with a protease inhibitor cocktail (Sigma) for $30 \mathrm{~min}$ on ice. After centrifugation at 13000 r.p.m. or $10000 \boldsymbol{g}$ for $20 \mathrm{~min}$, the supernatants were collected and stored at $-80^{\circ} \mathrm{C}$. Protein content was determined using the Bradford protein assay.

\section{Western blotting}

Samples were separated by SDS-PAGE (10\%) and transferred $(100 \mathrm{~V}, 3 \mathrm{~h})$ onto a nitrocellulose membrane (Bio-Rad). The blot was blocked with $5 \%(\mathrm{w} / \mathrm{v})$ milk and $0.1 \%(\mathrm{v} / \mathrm{v})$ Tween 20 in TBS at $4{ }^{\circ} \mathrm{C}$ overnight followed by incubation with $0.5 \mu \mathrm{g} / \mathrm{ml}$ goat anti-rat RAGE polyclonal antibody (Santa Cruz Biotechnology) or $0.5 \mu \mathrm{g} / \mathrm{ml}$ goat anti-rat SR-A polyclonal antibody (Santa Cruz Biotechnology) in 1\% (w/v) milk and $0.1 \%$ Tween 20 in TBS for $2 \mathrm{~h}$ at room temperature.

The membrane was washed thrice with $0.1 \%$ Tween 20 in TBS and incubated with $0.1 \mu \mathrm{g} / \mathrm{ml}$ anti-goat IgG-HRP antibody (Santa Cruz Biotechnology) in 5\% (w/v) milk and $0.1 \%(\mathrm{v} / \mathrm{v})$ Tween 20 in TBS for $1.5 \mathrm{~h}$ at room temperature. The membrane was again washed thrice with $0.1 \%$ Tween 20 in TBS and once with TBS. Relative quantity loading was confirmed using goat anti-rat $\beta$-actin antibody (Santa Cruz Biotechnology, Heidelberg, Germany) followed by using the secondary antibody described above. The bands were visualized using a chemiluminescent substrate (Thermo Scientific, Rockford, IL, USA), exposed to an X-ray film (Thermo Scientific) and quantified using the NIH Image/Gel Plotting analysis program (National Institutes of Health, Bethesda, MD, USA) (Rasband 1997-2004). The signals were standardized to the expression of $\beta$-actin.

\section{Statistical analysis}

The data are expressed as means \pm s.E.M., and data analysis was carried out using the SPSS 18.0 Software for Windows. Two-tailed Student's $t$-test and the Mann-Whitney $U$ test were used for parametric and non-parametric parameters respectively. The Spearman's rank correlation test was carried out to examine the associations between the parameters tested. Statistically significant difference was defined as a $P$ value $<0.05$.

\section{Results}

\section{Metabolic and hormonal parameters}

The high-AGE diet provoked several alterations in the metabolic and hormonal profiles between the two groups.

Published by Bioscientifica Ltd 
Although the low-AGE diet-fed female rats displayed increased weight gain compared with the high-AGE dietfed rats $(153.11 \pm 6.48$ vs $99.88 \pm 12.36 \mathrm{~g}, P=0.002)$, the latter were more insulin resistant at the end of feeding as revealed by the increased glucose and insulin levels in these rats compared with the low-AGE diet-fed group $(141.00 \pm 10.66$ vs $103.12 \pm 5.91 \mathrm{mg} / \mathrm{dl}, P=0.008$ and $2.20 \pm 0.286$ vs $0.98 \pm 0.139 \mu \mathrm{IU} / \mathrm{ml}, P=0.002$ respectively). Furthermore, the dietary exposure to high AGE levels provoked an hormonal dysregulation of the female reproductive system of the rats as revealed by the increased testosterone $(0.330 \pm 0.023$ vs $0.165 \pm 0.011 \mathrm{nmol} / \mathrm{l}$, $P<0.001)$ and the decreased $\mathrm{E}_{2}(10.94 \pm 0.56$ vs 20.44 $\pm 1.38 \mathrm{pmol} / \mathrm{l}, P<0.001)$ and progesterone $(16.01 \pm 2.21$ vs $37.81 \pm 2.69 \mathrm{nmol} / 1, P<0.001)$ levels in the high-AGE diet-fed rats compared with the low-AGE diet-fed ones. This metabolic phenotype can be attributed to the accumulation of AGEs in the body as revealed by the higher serum levels of AGEs in the high-AGE diet-fed rats $(6.70 \pm 0.22$ vs $4.71 \pm 0.36 \mathrm{U} / \mathrm{ml}, P<0.001)$.

\section{RAGE and SR-A expression in PBMCs}

To evaluate the role of RAGE and SR-A as scavenger receptors during exposure to dietary AGEs, we carried out western blotting for the detection of these receptors on PBMCs isolated from the low-AGE or high-AGE diet-fed rats. Indeed, the levels of both the receptors were downregulated in rats fed the high-AGE diet. More specifically, the expression of RAGE was decreased in the high-AGE diet-fed group when compared with the low-AGE diet-fed group $(55.04 \pm 3.71$ vs $100 \pm 29.08 \%, P=0.041)$. Additionally, the expression of SR-A showed a tendency towards lower levels in the high-AGE diet-fed group in comparison with the low-AGE diet-fed group $(37.12 \pm 3.49$ vs 100 $\pm 46.20 \%, P=0.11$; Fig. 1 ).

\section{Correlation analysis}

The negative impact of high AGE concentrations on the metabolic and hormonal regulation of the high-AGE diet-fed rats was indicated by the strong negative correlation of serum AGE levels with the levels of $\mathrm{E}_{2}$ $(r s=-0.800, P<0.001)$ and progesterone $(r s=-0.521$, $P=0.019)$ and the parallel positive correlation with those of insulin $(r s=0.584, P=0.005)$ and testosterone ( $r s=0.640, P=0.002$ ). The contribution of the scavenger receptors to this phenotype could be demonstrated by the fact that the expression of RAGE showed a negative correlation with insulin and testosterone levels $(r s=-0.581$,
$P=0.009$ and $r s=-0.432, P=0.047$ respectively) and a positive correlation with progesterone levels $(r s=0.473$, $P=0.044)$. Similarly, the expression levels of SR-A showed a tendency to a negative correlation with insulin levels ( $r s=-0.480, P=0.057$; Fig. 2).

A
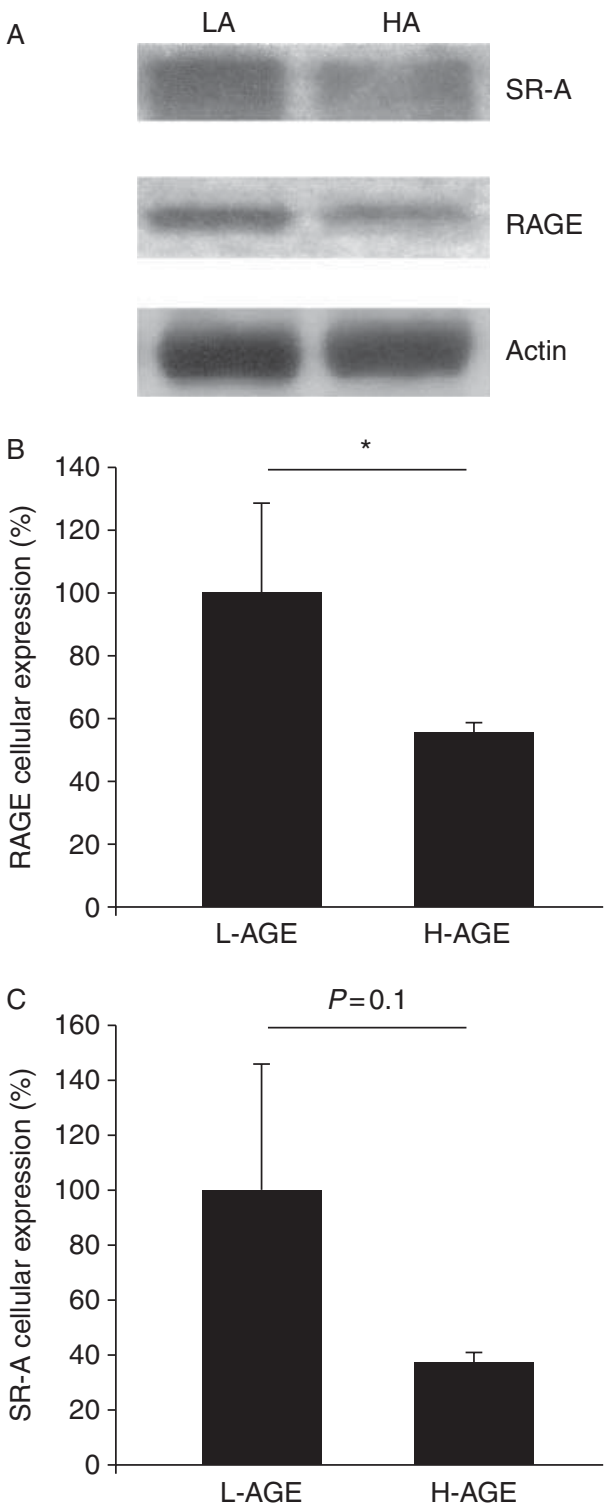

Figure 1

(A) Western immunoblot analysis of peripheral blood mononuclear cell (PBMC) lysates of low-AGE and high-AGE diet-fed rats (Low AGEs (LA) and High AGEs (HA) respectively) using specific antibodies targeting SR-A, RAGE and actin proteins. (B and C) Western blot signal of the SR-A and RAGE bands normalized to the intensity of the corresponding $\beta$-actin bands. In the graphs of (B and C), the mean normalized RAGE or SR-A signal amount of the low-AGE diet-fed rats is defined as $100 \%$ and related to the normalized signal intensity of the bands of the high-AGE diet-fed rats. Data are expressed as means \pm s.E.M. and $P \leq 0.05$ was considered significant (*).

Published by Bioscientifica Ltd. 

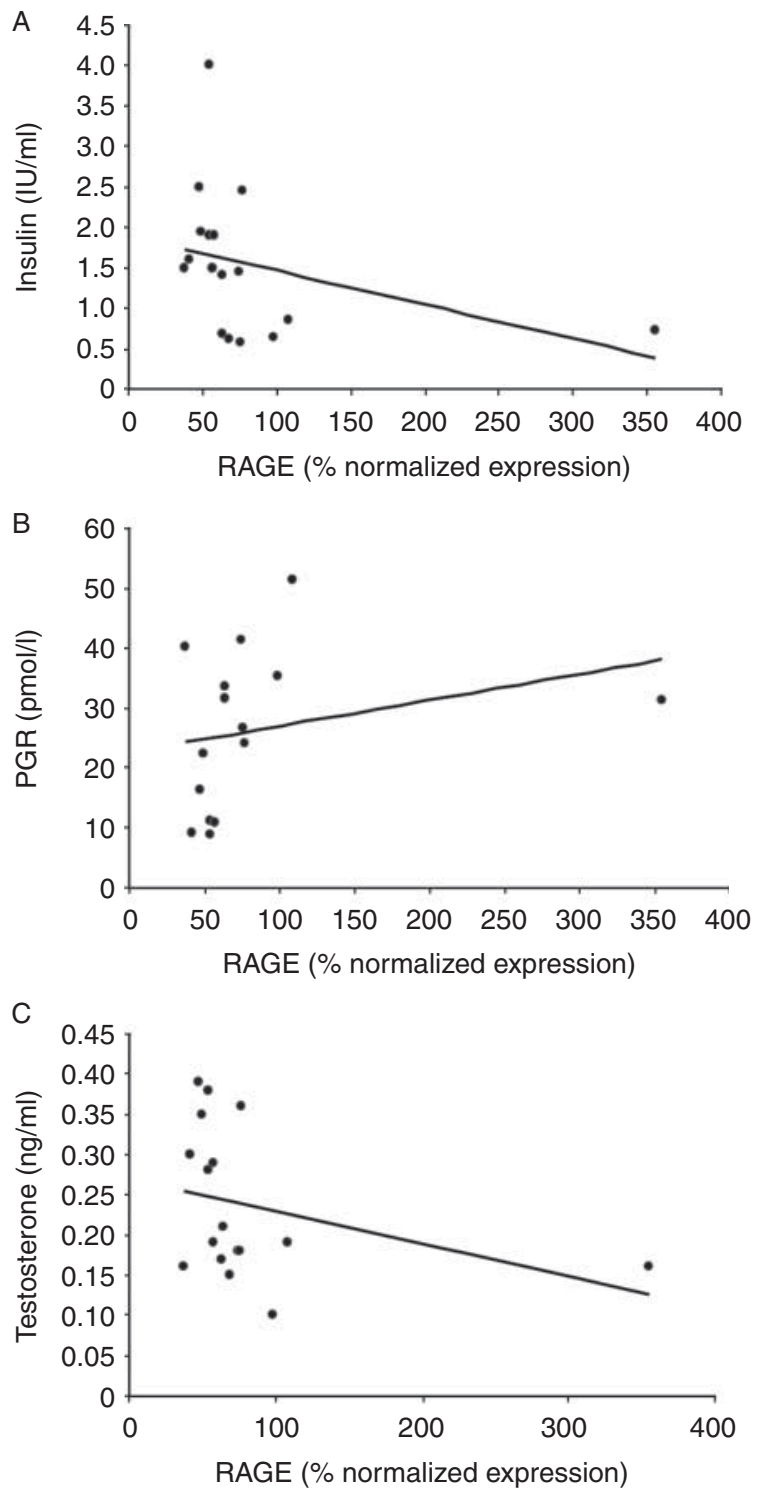

Figure 2

Negative correlation of RAGE expression on PBMCs with insulin (A) and testosterone (C) levels ( $r s=-0.581, P=0.009$ and $r s=-0.432, P=0.047$ respectively) and positive correlation with progesterone (B) levels $(r s=0.473, P=0.044)$.

\section{Discussion}

Current evidence indicates that the accumulation of AGEs in the body either via endogenous pathways or via exogenous intake is associated with the development of insulin resistance even in non-diabetic or non-obese individuals (de Assis et al. 2009, Tan et al. 2011). Apart from the metabolic dysregulation, AGEs are also able to induce further hormone-related malfunctions such as functional alterations of the female reproductive system
(Diamanti-Kandarakis et al. 2005, 2007a). However, the mechanism by which these endocrine phenomena, due to the accumulation of AGEs, are taking place is still unclear. The scavenger receptors, such as RAGE, SR-A, CD36 and LOX-1, can recognize AGEs and activate several cellular pathways promoting or dampening inflammatory and oxidative processes. Therefore, they have emerged as the major regulatory factors of AGE levels during AGEaccumulating pathophysiological conditions including ageing, diabetes, PCOS and Alzheimer's disease (Miyazaki et al. 2002, Murphy et al. 2005).

In this study, we demonstrated that the levels of RAGE and SR-A were decreased in peripheral monocytes of female rats fed a high-AGE diet compared with those fed a low-AGE diet. Furthermore, the expression of RAGE was correlated negatively with insulin and testosterone levels and positively with progesterone levels, while the expression of SR-A showed a tendency towards a negative correlation with insulin levels. These findings suggest a possible link between the expression of scavenger receptors and the metabolic dysregulation and hormonal dysfunction in the female reproductive system taking place under dietary exposure to high levels of AGEs. This is the first study to demonstrate the down-regulation of the expression of SR-A upon the accumulation of AGEs due to dietary glycotoxins and also the first study to correlate the expression of scavenger receptors with the hormonal imbalance of the female reproductive system.

Our data regarding the expression of RAGE are in agreement with the results of the studies of Miura et al. (2004) and Sourris et al. (2010), in which decreased monocytic expression of RAGE in AGE-related diseases such as diabetes, as a result of a negative feedback loop in the expression of RAGE, has been observed. Similarly, Leuner et al. (2012) reported increased insulin resistance in RAGE-deficient mice. On the other hand, the concentrations of the soluble forms of RAGE have been found to be elevated and correlated with increased concentrations of serum AGEs, indicating that the decreased cellular expression of RAGE could be attributed to increased shedding of the receptor or to a change in the alternative splicing process of the gene (Tan et al. 2006, Nakamura et al. 2007). Therefore, the decreased antioxidant defence due to a lower cellular expression of RAGE together with the increased levels of the soluble form can probably explain the endocrine or vascular complications present in AGE-related pathologies. In parallel, the expression of SR-A, which also showed a tendency towards decreased levels in the high-AGE diet-fed group, seems to contribute

Published by Bioscientifica Ltd. 
to the decreased clearance of AGEs, thus promoting AGE-related complications. Although SR-A-related published data are still controversial since high glucose or modified LDL are able to increase the expression of SR-A (Lam et al. 2004, Fukuhara-Takaki et al. 2005), while TNFa is able to decrease it in macrophages (Hsu et al. 1996), even these in vitro or in vivo data cannot be compared to the peripheral monocytic SR-A expression and have a lot of differences to the AGEs receptors' regulation in the dietary glycotoxins model that we performed here.

Another novel finding of this study is the possible link between the expression of scavenger receptors, such as RAGE, and the hormonal dysregulation of the female reproductive system, since the monocytic expression of RAGE was negatively correlated with testosterone levels and positively correlated with progesterone levels. This association could imply either a direct interfering role of AGEs in ovarian steroidogenesis with increased testosterone and ovulatory dysregulation with poor progesterone production or an indirect role via the aggravation of insulin resistance, which, in turn, deteriorates the ovarian dysfunction (Diamanti-Kandarakis et al. 2005). Additionally, the increased levels of AGEs and RAGE expression, demonstrated by our group in rat and human ovaries (Diamanti-Kandarakis et al. 2007a), could be explained by the decreased expression of scavenger receptors in circulating monocytes, which, in turn, leads to an increased deposition of AGEs in endocrine-related tissues such as the ovaries.

In conclusion, in this study, we demonstrated that dietary AGEs besides their implication for the development of insulin resistance can also contribute to the hormonal dysregulation of the female reproductive system, as indicated by increased testosterone levels and decreased $\mathrm{E}_{2}$ and progesterone levels. This phenomenon is probably linked to the reduced monocytic expression of scavenger receptors of AGEs such as RAGE and SR-A, which, in turn, results in a higher deposition of AGEs in peripheral endocrine tissues and leads to endocrinerelated abnormalities and diseases.

\section{Declaration of interest}

The authors declare that there is no conflict of interest that could be perceived as prejudicing the impartiality of the research reported.

\section{Funding}

This research did not receive any specific grant from any funding agency in the public, commercial or not-for-profit sector.

\section{References}

de Assis AM, Rieger DK, Longoni A, Battu C, Raymundi S, da Rocha RF, Andreazza AC, Farina M, Rotta LN, Gottfried C et al. 2009 High fat and highly thermolyzed fat diets promote insulin resistance and increase DNA damage in rats. Experimental Biology and Medicine 234 1296-1304. (doi:10.3181/0904-RM-126)

Cai W, He JC, Zhu L, Chen X, Wallenstein S, Striker GE \& Vlassara H 2007 Reduced oxidant stress and extended lifespan in mice exposed to a low glycotoxin diet: association with increased AGER1 expression. American Journal of Pathology 170 1893-1902. (doi:10.2353/ajpath.2007.061281)

Cai W, He JC, Zhu L, Chen X, Zheng F, Striker GE \& Vlassara H 2008 Oral glycotoxins determine the effects of calorie restriction on oxidant stress, age-related diseases, and lifespan. American Journal of Pathology 173 327-336. (doi:10.2353/ajpath.2008.080152)

Cai W, Ramdas M, Zhu L, Chen X, Striker GE \& Vlassara H 2012 Oral advanced glycation endproducts (AGEs) promote insulin resistance and diabetes by depleting the antioxidant defenses AGE receptor-1 and sirtuin 1. PNAS 109 15888-15893. (doi:10.1073/pnas.1205847109)

Chatzigeorgiou AE, Lembessis PE, Mylona-Karagianni CF, Tsouvalas EA, Diamanti-Kandarakis E \& Kamper EF 2010 CD40 expression and its association with low-grade inflammation in a Greek population of type 1 diabetic juveniles: evidence for differences in CD40 mRNA isoforms expressed by peripheral blood mononuclear cells. Experimental and Clinical Endocrinology \& Diabetes 118 38-46. (doi:10.1055/s-00291224151)

Diamanti-Kandarakis E, Piperi C, Kalofoutis A \& Creatsas G 2005 Increased levels of serum advanced glycation end-products in women with polycystic ovary syndrome. Clinical Endocrinology 62 37-43. (doi:10.1111/j.1365-2265.2004.02170.x)

Diamanti-Kandarakis E, Piperi C, Korkolopoulou P, Kandaraki E, Levidou G, Papalois A, Patsouris E \& Papavassiliou AG 2007a Accumulation of dietary glycotoxins in the reproductive system of normal female rats. Journal of Molecular Medicine 85 1413-1420. (doi:10.1007/s00109-0070246-6)

Diamanti-Kandarakis E, Piperi C, Patsouris E, Korkolopoulou P, Panidis D, Pawelczyk L, Papavassiliou AG \& Duleba AJ 2007b Immunohistochemical localization of advanced glycation end-products (AGEs) and their receptor (RAGE) in polycystic and normal ovaries. Histochemistry and Cell Biology 127 581-589. (doi:10.1007/s00418-006-0265-3)

Fukuhara-Takaki K, Sakai M, Sakamoto Y, Takeya M \& Horiuchi S 2005 Expression of class A scavenger receptor is enhanced by high glucose in vitro and under diabetic conditions in vivo: one mechanism for an increased rate of atherosclerosis in diabetes. Journal of Biological Chemistry 280 3355-3364. (doi:10.1074/jbc.M408715200)

Hsu HY, Nicholson AC \& Hajjar DP 1996 Inhibition of macrophage scavenger receptor activity by tumor necrosis factor- $\alpha$ is transcriptionally and post-transcriptionally regulated. Journal of Biological Chemistry 271 7767-7773. (doi:10.1074/jbc.271.13.7767)

Kandaraki E, Chatzigeorgiou A, Piperi C, Palioura E, Palimeri S, Korkolopoulou P, Koutsilieris M \& Papavassiliou AG 2012 Reduced ovarian glyoxalase-I activity by dietary glycotoxins and androgen excess: a causative link to polycystic ovarian syndrome. Molecular Medicine 18 1183-1189. (doi:10.2119/molmed.2012.00293)

Lam MC, Tan KC \& Lam KS 2004 Glycoxidized low-density lipoprotein regulates the expression of scavenger receptors in THP-1 macrophages. Atherosclerosis 177 313-320. (doi:10.1016/j.atherosclerosis.2004. 08.003)

Leuner B, Max M, Thamm K, Kausler C, Yakobus Y, Bierhaus A, Sel S, Hofmann B, Silber RE, Simm A et al. 2012 RAGE influences obesity in mice. Effects of the presence of RAGE on weight gain, AGE accumulation, and insulin levels in mice on a high fat diet. Zeitschrift für Gerontologie und Geriatrie 45 102-108. (doi:10.1007/s00391011-0279-x) 
Miura J, Uchigata Y, Yamamoto Y, Takeuchi M, Sakurai S, Watanabe T, Yonekura H, Yamagishi S, Makita Z, Sato A et al. 2004 AGE downregulation of monocyte RAGE expression and its association with diabetic complications in type 1 diabetes. Journal of Diabetes and its Complications 18 53-59. (doi:10.1016/S1056-8727(02)00281-7)

Miyazaki A, Nakayama H \& Horiuchi S 2002 Scavenger receptors that recognize advanced glycation end products. Trends in Cardiovascular Medicine 12 258-262. (doi:10.1016/S1050-1738(02)00171-8)

Mukhopadhyay S \& Mukherjee TK 2005 Bridging advanced glycation end product, receptor for advanced glycation end product and nitric oxide with hormonal replacement/estrogen therapy in healthy versus diabetic postmenopausal women: a perspective. Biochimica et Biophysica Acta 1745 145-155. (doi:10.1016/j.bbamcr.2005.03.010)

Murphy JE, Tedbury PR, Homer-Vanniasinkam S, Walker JH \& Ponnambalam S 2005 Biochemistry and cell biology of mammalian scavenger receptors. Atherosclerosis 182 1-15. (doi:10.1016/j.atherosclerosis.2005.03.036)

Nakamura K, Yamagishi SI, Matsui T, Adachi H, Takeuchi M \& Imaizumi T 2007 Serum levels of soluble form of receptor for advanced glycation end products (sRAGE) are correlated with AGEs in both diabetic and non-diabetic subjects. Clinical and Experimental Medicine 7 188-190. (doi:10.1007/s10238-007-0146-7)

Neyen C, Pluddemann A, Roversi P, Thomas B, Cai L, van der Westhuyzen DR, Sim RB \& Gordon S 2009 Macrophage scavenger receptor A mediates adhesion to apolipoproteins A-I and E. Biochemistry 48 11858-11871. (doi:10.1021/bi9013769)

Niwa T 2006 Mass spectrometry for the study of protein glycation in disease. Mass Spectrometry Reviews 25 713-723. (doi:10.1002/mas. 20089)
Rasband WS 1997-2004 ImageJ. Bethesda, Maryland, USA: National Institutes of Health. http://rsb.info.nih.gov/ij/.

Sourris KC \& Forbes JM 2009 Interactions between advanced glycation endproducts (AGE) and their receptors in the development and progression of diabetic nephropathy - are these receptors valid therapeutic targets. Current Drug Targets 10 42-50. (doi:10.2174/138945009787122905)

Sourris KC, Harcourt BE, Penfold SA, Yap FY, Morley AL, Morgan PE, Davies MJ, Baker ST, Jerums G \& Forbes JM 2010 Modulation of the cellular expression of circulating advanced glycation end-product receptors in type 2 diabetic nephropathy. Experimental Diabetes Research 2010 974681. (doi:10.1155/2010/974681)

Tan KC, Shiu SW, Chow WS, Leng L, Bucala R \& Betteridge DJ 2006 Association between serum levels of soluble receptor for advanced glycation end products and circulating advanced glycation end products in type 2 diabetes. Diabetologia 49 2756-2762. (doi:10.1007/ s00125-006-0394-1)

Tan KC, Shiu SW, Wong Y \& Tam X 2011 Serum advanced glycation end products (AGEs) are associated with insulin resistance. Diabetes/Metabolism Research and Reviews 27 488-492. (doi:10.1002/dmrr.1188)

Tanaka N, Yonekura H, Yamagishi S, Fujimori H, Yamamoto Y \& Yamamoto H 2000 The receptor for advanced glycation end products is induced by the glycation products themselves and tumor necrosis factor- $\alpha$ through nuclear factor- $\kappa \mathrm{B}$, and by $17 \beta$-estradiol through Sp-1 in human vascular endothelial cells. Journal of Biological Chemistry 275 25781-25790. (doi:10.1074/jbc.M001235200)

Uribarri J, Cai W, Ramdas M, Goodman S, Pyzik R, Chen X, Zhu L, Striker GE \& Vlassara H 2011 Restriction of advanced glycation end products improves insulin resistance in human type 2 diabetes: potential role of AGER1 and SIRT1. Diabetes Care 34 1610-1616. (doi:10.2337/dc11-0091)

Received in final form 26 June 2013

Accepted 3 July 2013

Accepted Preprint published online 3 July 2013
() 2013 Society for Endocrinology Printed in Great Britain
Published by Bioscientifica Ltd. 